\begin{tabular}{cc} 
Sharif University of Technology \\
Scientia Iranica \\
SCIENTIA & Transactions B: Mechanical Engineering \\
I RAN I CA & \\
\hline
\end{tabular}

\title{
Analysis of change in the state of hydraulic drive of machines in operation according to the diagnostic results
}

\author{
N.G. Grinchar ${ }^{a}$, P.A. Sorokin ${ }^{a}$, V.A. Karpychev ${ }^{\text {,** }}$, and K.A. Sergeev \\ a. Department of Track Machines, Construction Machines and Robot Systems, Russian University of Transport, 127994, 9 \\ Obrazcova Str., Moscow, Russian Federation. \\ b. Department of Machine Science, Design, Standardization and Certification, Russian University of Transport, 127994, 9 \\ Obrazcova Str., Moscow, Russian Federation. \\ c. Department of Non-Traction Rolling Stock, Russian University of Transport, 127994, 9 Obrazcova Str., Moscow, Russian \\ Federation.
}

Received 24 January 2018; accepted 18 June 2018

\section{KEYWORDS}

Diagnostic parameter;

Hours in operation;

Hydraulic drive;

Economic

expenditures;

Performance

capability.

\begin{abstract}
Technical diagnostics is a sphere of knowledge embracing theory, methods, and means of defining the technical state of the objects. It is necessary for provision of security, functional reliability, and efficiency of the technical object operation, as well as for reduction in the costs of technical maintenance and the idle time losses caused by failures and premature shutdowns for maintenance. The objective of this paper is to analyze the change in the state of hydraulic drive of machines in operation according to the diagnostic results. In order to achieve the set objective, the authors used various experimental methods. The paper considers mutual influence of maintenance and technical diagnostics of hydrostatic drives of construction, track, and some other mobile machines. It is shown that introduction of technical diagnostics allows transferring from the system of planned preventive repairs to the system of servicing the machines based on their actual technical state, which helps in completely using the resource of a series of expensive aggregates. The authors described several basic characteristics of change in the volume effectiveness of the hydraulic sets in operation.
\end{abstract}

(C) 2020 Sharif University of Technology. All rights reserved.

\section{Introduction}

The modern economic situation in Russia makes the scientists, economists, and engineers face a series of relevant issues connected with effective functioning of the railroad transport. The main part of the fleet of the modern machines for construction and maintenance of

\footnotetext{
*. Corresponding author. Tel.: +84999782356 E-mail addresses: nggrin@yandex.ru (N.G. Grinchar); pavalsor@rambler.ru(P.A.Sorokin); kv119@yandex.ru (V.A. Karpychev); vagon-7@yandex.ru (K.A. Sergeev)
}

doi: $10.24200 /$ sci. 2018.50340 .1644 the railways is the machines with volumetric hydraulic drive, the most widely used due to their well-known advantages.

The main peculiarity of operation of these machines is the fact that the entire volume of work is performed at the railroad lines in the "gap" in a limited time-frame. Availability of the machines significantly depends on the state of hydraulic drive, which is the reason for over $50 \%$ of the failures in the machines. Traditional methods ensuring reliability of hydraulic drives based on the system of planned preventive repairs do not fully ensure the necessary result, on the one hand, and cause great material and financial expenditures, on the other hand. 
The system of maintenance and planned preventive repairs started to be formulated in the $1930 \mathrm{~s}$, when the first "Rules for Servicing Tractors and Their Drawn Equipment and for Their Field Maintenance" (1932) implied 8 stages of performing the work with obligatory change of a series of details. Thereafter, the rules served as a prototype for development of the maintenance system and planned preventive repairs of other machines. However, the idea, proposed in as early as the 1940s by Professor G.V. Vedenyapin concerning the performance of the work on demand, has not been fully implemented up to now.

The modern situation in over the last two decades and change in the methods and means of control necessitate improving the theory and practice of hydraulic drives operation in construction and road machines, particularly by application of technical diagnostics. Technical diagnostics allows for controlling the state of hydraulic drive of the machines and more precisely setting the terms and volume of the servicing and maintenance work; helps in supporting availability of the machines for performing the work; and forecasts the residual operating time and progress in hydraulic drive, its nodes, and specific devices.

Development of the methods and means of technical diagnostics of hydraulic drives leads to a new situation in operation and makes it possible to apply the individual approach to solving the tasks of maintenance policy. Technical diagnostics allows for eliminating redundant assembly/disassembly work, defining real need in regulations, revealing and controlling the main performance indicators of hydraulic drive of the machines in operation, and adjusting the terms of technical maintenance depending on intensity of the works. It also allows for controlling the state of new or maintained machines during the warranty period, which contributes to higher quality of manufacturing and maintenance.

Technical diagnostics of hydraulic drives of the machines is a relatively new trend in science of mobile machines operation. Its bases were formed in the early 1970 s $[1,2]$, when volumetric hydraulic drive gained widespread use. The issues of technical diagnostics of complicated systems were studied by Birger [3], Verzakova [4], Petrova [5], Kim [6], and Terskikh [7]. The issues of diagnostics of volumetric hydraulic drive were investigated in the papers by Alekseeva et al. [8], Abramov and Kharazov [9], Korzhova [10], Makarova and Sokolov [11], Maltseva [12], Morozova [13], Pavlov [14], Ponomarenko [15], Sidorov [16], Shumeyko [17], Bagin [18], Baryshev [19], Nikitin [20], and others.

\section{Materials and methods}

Study of the theory and practice of maintenance and technical diagnostics reveals that the current methods of ensuring reliability and organization of the maintenance of hydroficated machines at the railroad transport do not lead to the most effective solutions for process management to ensure readiness and performance capability from the perspectives of economy, resourcesaving, and technology and equipment. Development of the mechanization processes of track and transport work requires working out scientific substantiation of the decisions made in the organization of technical functioning; this is particularly important in forecasting the residual resource of hydraulic drive in general and particular devices.

The most efficient way of solving a series of issues related to this problem is precise consideration of their interconnection with each other and with adjacent factors as well as the ways of influence on these factors. It requires the analysis of applicability of private theories and developments to create a single system of technical diagnostics for hydraulic drives including both technical means and methodological developments of managerial decisions in exploiting hydraulic drives as complicated systems.

The complexes of organizational and technical measures for maintenance and repair carried out as planned are generally integrated in a single planned preventive system. Apparently, the minimum economic expenditures will be achieved when the applied system of maintenance and planned preventive repairs (hereinafter MNT and PPR) ensures rather close compliance of the planned terms for performing the repairs with the actual time they are needed on the one hand, and compliance of the volume of repairs with the actual requirements on the other hand $[1,2,5,7,9,11,12,14,15,18$ 23]. Otherwise, additional expenditures connected with unplanned repairs and overestimated volume of planned maintenances are inevitable.

\section{Results and discussion}

The current PPR system, as a rule, implies MNT and PPR frequency of approximately $10 \%$, which ensures full exploitation of the resource, while the rest $90 \%$ are repaired ahead of time. Practice shows that considering indicators such as the time between failures, fuel and service parts consumption, etc. allows for correcting the time of placing the machines under repair, thus increasing their lifetime. Figure 1 shows the generalized regularity of expenditures for support of reliability, and the maintenance frequency and operating time of the machines. Let us consider the maintenance frequency for the hydraulic drives of machines according to PPR without application of the diagnostic means. The main parameter characterizing the change in the technical state of hydraulic drive in general and its particu- 


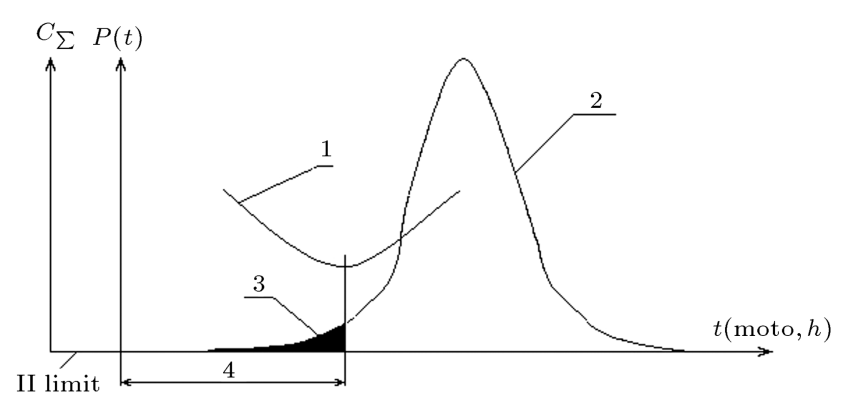

(1) Aggregate expenditures on maintenance and repair among the fleet; (2) Distribution of the lifetimes of the hydraulic drive main aggregates; (3) Unplanned repairs (depending on the PPR frequency);

(4) Optimal time of maintenance and repair.

Figure 1. Dependency of the expenditures on reliability of the support of the machines.

lar elements constitute the volumetric performance $[1,2,5,7,9,11,12,14,18-21]$.

Figure 2 shows the change in the volumetric performance for a group of machines under maintenance and repair with the set frequency without applying the diagnostic means. Section $1\left(t_{1}\right)$ in Figure 2 characterizes the changes in the volumetric performance of various machines, while section $2\left(t_{2}\right)$ represents the function of time between failures distribution density for the complex of machines.

In the system of the planned preventive repairs, maintenance of all the machines should be carried out each time in the same period of operation $\left(t_{1}, t_{2}\right.$, and $t_{3}$ ) when the probability of failure emergence for only one element is insignificant. At such frequency, there is no need for technical diagnostics, because an overwhelming majority of the machines during maintenance will have sufficient resources, i.e., there is capacity for operating in significant time periods with-

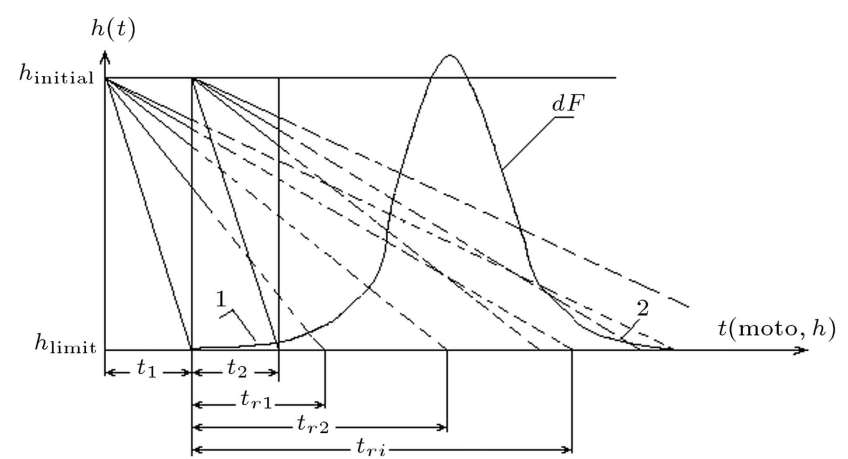

Figure 2. Change in volumetric performance of hydraulic drive for a group of track machines with the set frequency of maintenance without applying diagnostic means: $h_{\text {initial }}$ : nominal (initial) value of volumetric performance; $h_{\text {limit }}$ : limit value of volumetric performance; $t_{i}$ : frequency of MNT or repair; $t_{o i}$ : residual (underutilized) resource of hydraulic aggregates; $d F$ : distribution density of the hydraulic drive operating time for a group of machines up to the limit state. out interference, ensuring exploitation of the machine up to the next planned repair with high probability.

The maintenance and repair appointed by considering the Technical Documentation (TD) comprises diagnostic operations carried out in certain periods $t_{i}$. Therewith, the technical documentation should contain the values of the volumetric performance and other parameters of the hydraulic drive's state, at which failure-free exploitation up to the next examination is possible. Implementation of such maintenance is shown at Figure 3.

Apparently, in the point of the first examination, $t_{d 1}$, values of the state parameters may not reach the critical value, i.e., the machines may operate without maintenance up to the next examination. Values of volumetric performance at point $t_{d_{2}}$ for two machines exceed $\eta_{g}$; therefore, the machines should be repaired. However, one of them can operate without failure up to the next examination without maintenance, i.e., its parameter will reach the limit value, $\eta_{n}$, at point $T_{3}$.

Thus, preventive maintenance and repair of the machine by the application of technical diagnostics is characterized by the fact that due to more complete exploitation of the tolerance range for deviation of the state parameter and conduction of the diagnostics, the share of the complete implementation of the resources of the machine's elements increases.

The main diagnostic parameters for hydraulic drive and its elements are volumetric losses of the operating liquid and performance general and volumetric at the standard pressure. If in the drive system, the set pressure does not develop, it is definitely defective and repairable.

The model of change in the diagnostic parameter is based on the statistics of change in the volumetric performance during the operation.

The experimental dependencies of change on the volumetric performance are of parabolic shape. Petrov [5] suggests conducting research on the function parameters, $\eta=f(t)$, based on the assumption that they are of the square shape, represented as follows:

$$
\eta=a t^{2}+b t+c .
$$

The value of the parameter $h$ must be equally spaced (Eq. (2)):

$$
t_{k+1}-t_{k}=h=\operatorname{const}(k=1,2,3, \ldots, n),
$$

allowing to keep record of the mean value $t_{\text {mean }}=\left(t_{1}+\right.$ $\left.t_{n}\right) / 2$ in the integral parts of the pace, having selected preliminarily an odd number of experimental data in five points of the non-failure operating time.

Then, the following equation in obtained:

$$
\eta=a_{1}\left(\frac{t-t_{c p}}{n}\right)+b_{1}\left(\frac{t-t_{c p}}{n}\right)+c^{\prime},
$$




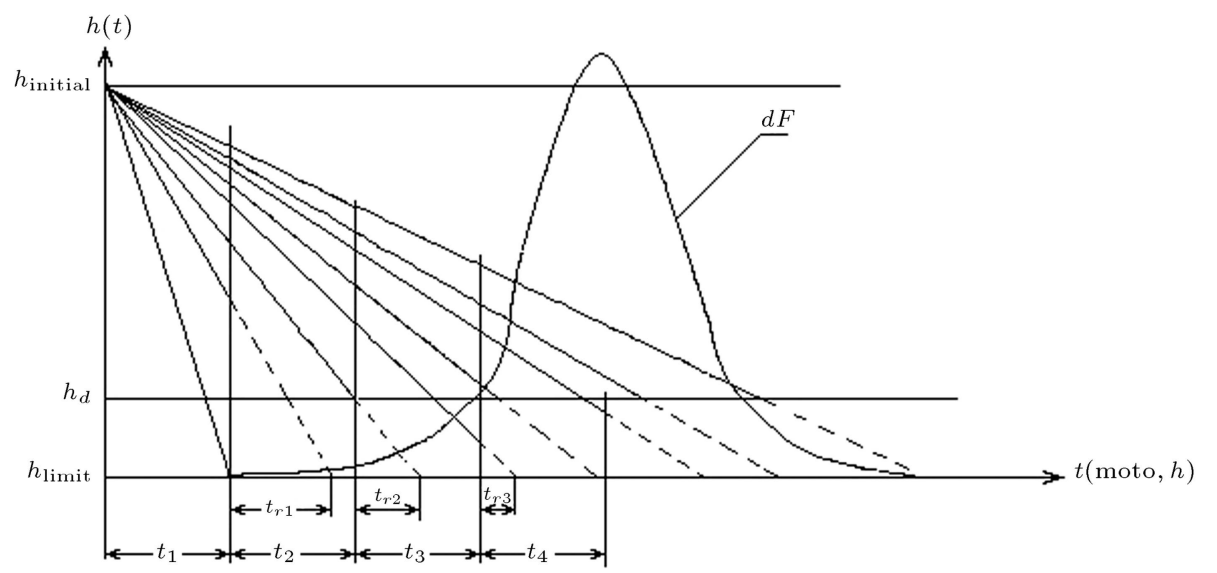

Figure 3. Change in volumetric performance of hydraulic drive for a group of track machines in control preventive maintenance with application of the diagnostic means: $h_{\text {initial }}$ : Nominal (initial) value of the volumetric performance; $H_{\text {limit }}$ : limit value of volumetric performance; $H_{d}$ : accepted value of volumetric performance; $t_{i}$ : frequency of preventive examinations; $t_{o i}$ : residual (underutilized) resource of hydraulic aggregates; dF: distribution density of the hydraulic drive operating time for a group of machines up to the limit state.

where parameters $a_{1}, b_{1}$, and c are calculated by the following formulae with the odd number of the data (in 5 points):

$$
\begin{aligned}
& a_{1}=\frac{1}{3 H_{2}}\left[3 \sum_{k=1}^{N} \eta_{k} \cdot(k-M)^{2}-\frac{N^{2}}{4} \cdot \sum_{k=1}^{N} \eta_{k}\right], \\
& b_{1}=\frac{1}{H_{1}} \cdot \sum_{1=k}^{N} \eta_{k} \cdot(k-M) ; \quad c=\eta_{k}^{c p}-\frac{H_{1}}{N} \cdot a_{1},
\end{aligned}
$$

where:

$$
\begin{aligned}
& H_{1}=N\left(N^{2}-1\right) / 12 ; \\
& H_{2}=N\left(N^{2}-1\right)\left[N^{2}-4\right] / 180 .
\end{aligned}
$$

Values of $H_{i}$ are presented in the annexes of the mathematic statistics. When $H_{1}=10$ and $3 H_{2}=42$ we get an expression of the following form:

$$
\eta=a t^{2}+b(3) \text {. }
$$

Eq. (6) is presented as preferable based on the following parameters. By differentiating expression (1) with respect to $t$, we obtain $\mathrm{Eq}$. (7):

$$
\eta^{\prime}=2 a t+b .
$$

However, at $t=0$ (i.e., prior to exploitation), $\eta^{\prime}$ is also apparently equal to 0 , because there is no wear phenomenon. But in this case also $b=0$, and thus we obtain Expression (3). Expression (3) should be apparently deemed as just formal description of the change in the nature of the volumetric performance during the operation, which may be good in some cases.

Physical meaning of Eq. (3) is narrowed down to the following: The tempo of the volumetric performance drop has an ascending value, which is explained by accumulation of the wear debris and abrasive materials in the operating liquid on the one hand, and increase in the friction and projectile forces in micrometric pairs, on the other hand.

For small time sections, the nature of the change in volumetric performance is satisfactorily described by linear dependence [9]. Let $\eta_{1}$ be defined in point $t_{1}$ and $\eta_{2}$ in point $t_{2}$. Here, Eq. (8) will look as follows:

$$
\eta^{\prime}=\frac{\eta_{1}-\eta_{2}}{t_{2}-t_{1}} .
$$

Let us name $\eta$ average velocity of change at time interval $\left(t_{1}, t_{2}\right)$. To assume that this velocity is further preserved during some section of time $\tau \leq\left(t_{2}-t_{1}\right)$, MNT, namely the value of volumetric performance, may be predicted, which after $\tau$ operating hours is equal to the following equation:

$$
\eta\left(t_{i}+\eta\right)=\eta_{i}-\eta^{\prime} \cdot \tau .
$$

As practice shows, for small time intervals, $\tau$, the considered allowance is correct (approximately for the interval of 240-300 hours of operating time according to the hour-meter of the machine).

For a group of machines, the area of lowered volumetric performance will apparently be limited by the following values (Eq. (10)):

$$
\begin{aligned}
& \eta_{1}=-A_{1} t^{2}+B, \\
& \eta_{2}=-A_{2} t^{2}+B,
\end{aligned}
$$

where $B$ is the initial value of the volumetric performance.

Definition of particular values of the dependency parameters (Eq. (10)) requires the following data: minimum and maximum operating times for the limit state, initial and limit values of volumetric performance. The 
Table 1. Parameters of change in volumetric performance of hydraulic drives.

\begin{tabular}{|c|c|c|c|c|c|c|}
\hline \multirow[t]{2}{*}{ Hydraulic valves } & \multicolumn{2}{|c|}{$\begin{array}{c}\text { Single-bucket } \\
\text { excavators }\end{array}$} & \multicolumn{2}{|c|}{$\begin{array}{c}\text { Transport construction } \\
\text { machines }\end{array}$} & \multicolumn{2}{|l|}{$\begin{array}{c}\text { Track } \\
\text { machines }\end{array}$} \\
\hline & $\frac{A_{\max } \div A_{\min }}{A^{\operatorname{mean}}} \cdot 10^{-6}$ & $B$ & $\frac{A_{\max } \div A_{\min }}{A_{\operatorname{mean}}} \cdot 10^{-6}$ & $B$ & $\frac{A_{\max } \div A_{\min }}{A^{\operatorname{mean}}} \cdot 10^{-6}$ & $B$ \\
\hline $\begin{array}{l}\text { Roll drive } \\
\text { (in general) }\end{array}$ & $\frac{0.012 \div 0.065}{0.0385}$ & 0.895 & $\frac{0.070 \div 1.40}{0.735}$ & 0.87 & $\frac{0.0684 \div 0.312}{0.127}$ & 0.875 \\
\hline $\begin{array}{l}\text { Linear motion drive } \\
\quad \text { (in general) }\end{array}$ & $\frac{0.008 \div 0.050}{0.029}$ & 0.94 & $\frac{0.050 \div 1.30}{0.675}$ & 0.91 & $\frac{0.076 \div 0.304}{0.1353}$ & 0.92 \\
\hline $\begin{array}{l}\text { Axial piston } \\
\text { hydraulic machines }\end{array}$ & $\frac{0.00395 \div 0.0283}{0.01612}$ & 0.95 & $\frac{0.029 \div 0.103}{76}$ & 0.95 & $\frac{0.0066 \div 0.088}{0.0163}$ & 0.95 \\
\hline $\begin{array}{l}\text { Gear and vane pumps } \\
\text { (for track machines) }\end{array}$ & $\frac{0.055 \div 0.22}{0.091}$ & 0.92 & $\frac{0.037 \div 1.16}{0.598}$ & 00.92 & $\frac{0.053 \div 0.249}{0.098}$ & 0.93 \\
\hline hydraulic cylinders & $\frac{0.00088 \div 0.0505}{0.02569}$ & $\sim 1.0$ & $\frac{0.003 \div 0.01}{6.5}$ & $\sim 1.0$ & $\frac{0.0012 \div 0.05}{0.0037}$ & $\sim 1.0$ \\
\hline Spool valves & $\frac{0.00343 \div 0.01236}{0.007895}$ & 0.99 & $\frac{0.0101 \div 0.022}{0.1165}$ & 0.99 & $\frac{0.0021 \div 0.0044}{0.00297}$ & 0.99 \\
\hline
\end{tabular}

initial value of the diagnostic parameter, $B$, seems to corroborate their certified values for specific devices of hydraulic drive, because in new devices, their spread is insignificant and they may be neglected. However, for a particular group of devices, parameter $B$ will be equal to:

$$
B=\prod_{i=1}^{n} B_{i} .
$$

The data obtained during the research conducted at the department "Track and Construction Machines and Robot Systems" of the Russian University of Transport (Moscow State University of Railway Engineering) allowed obtaining the data summarized in Table 1. Relevant dependencies are presented in Figures 4-9.

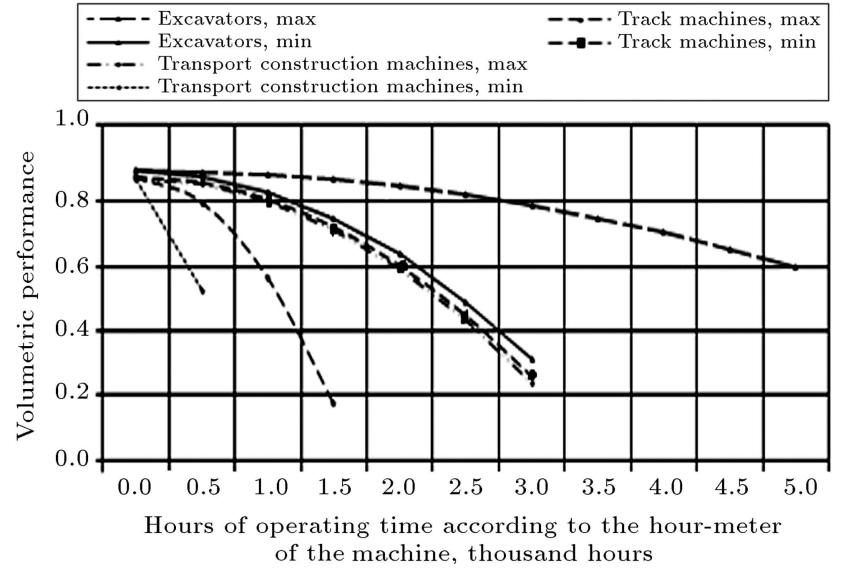

Figure 4. Change in volumetric performance of roll drive.

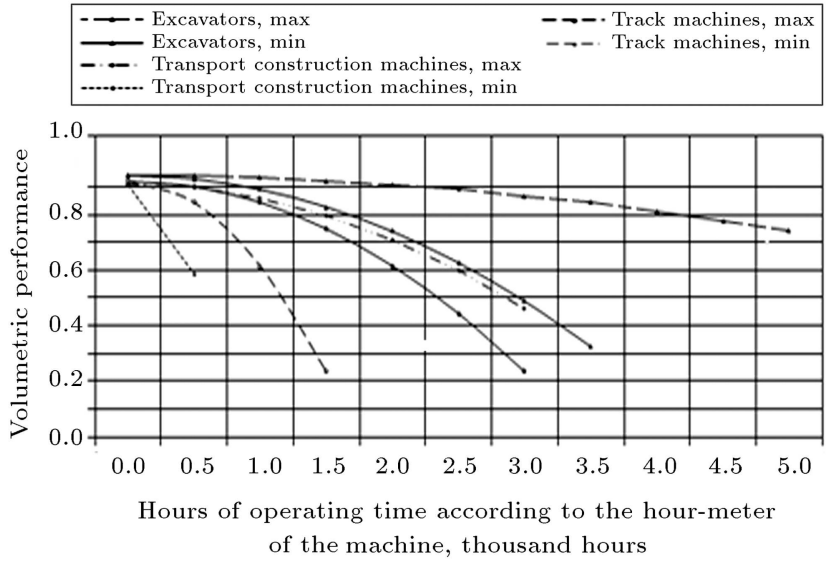

Figure 5. Change in volumetric performance of linear motion drive.

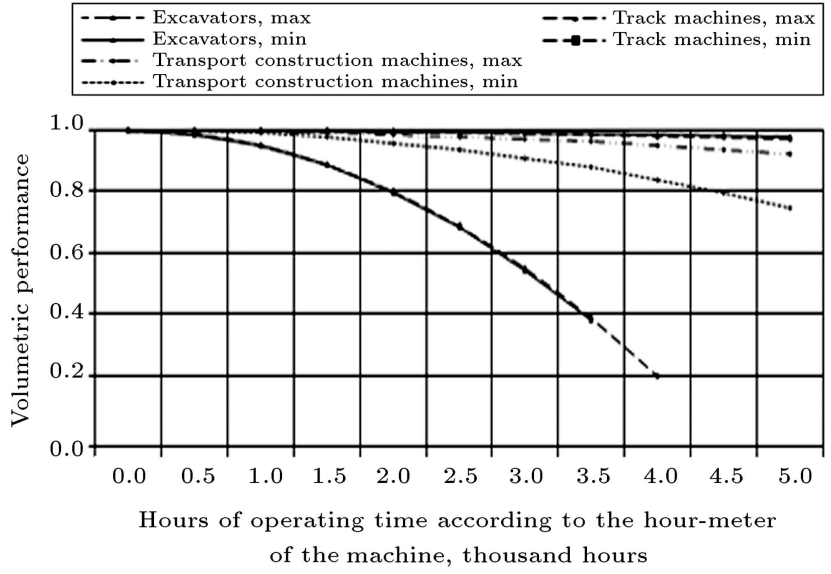

Figure 6. Change in volumetric performance of hydraulic cylinders. 


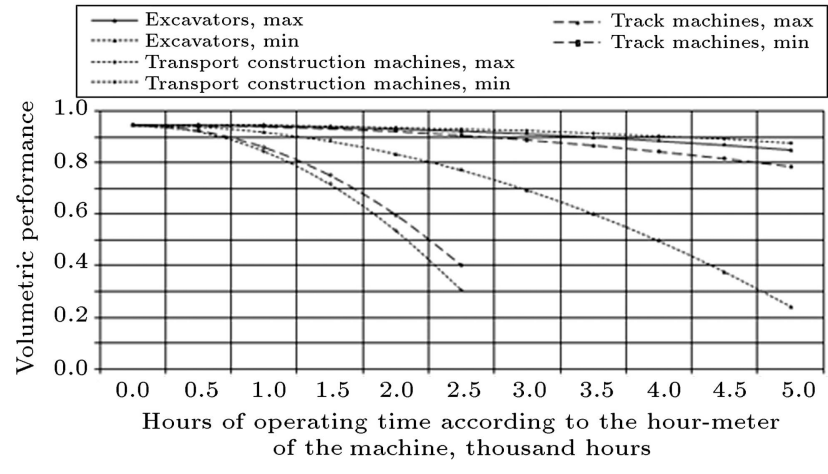

Figure 7. Change in volumetric performance of axial-piston hydraulic machines.

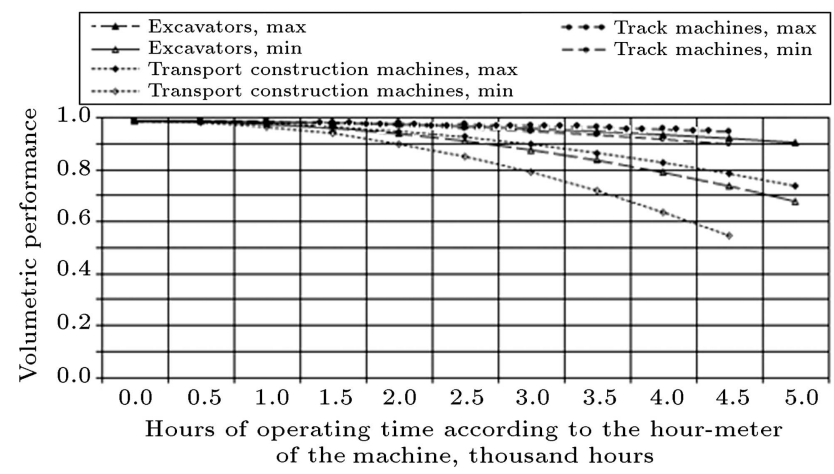

Figure 8. Change in volumetric performance of spool valves.

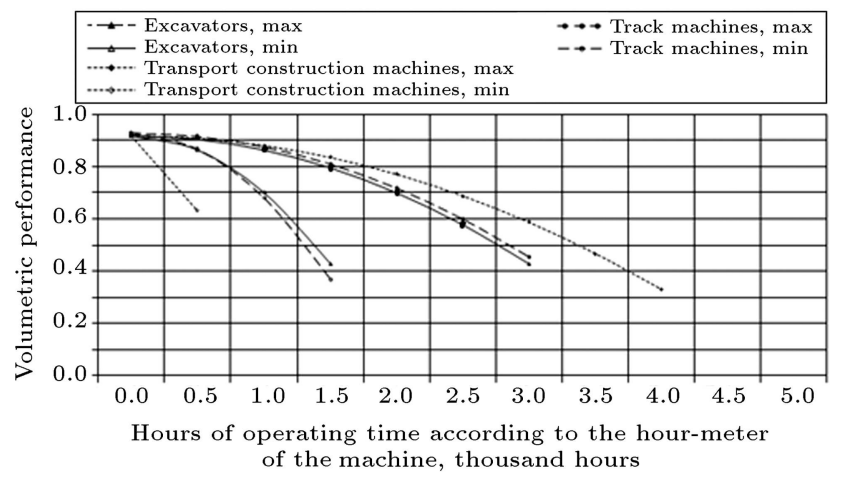

Figure 9. Change in volumetric performance of gear and vane pumps.

\section{Conclusion}

Increase in the exploitation of complicated and expensive technical systems, including hydraulic drives applied in various industries as executive organs in the control systems and automation of the production processes as well as drives of operating machines' organs, and the requirement for security, no-failure operation, and durability lend assessment of the technical state a considerable importance. Efficiency of exploitation of such machines to a great extent depends on availability of the modern methods and means for diagnostics of hydraulic drives. Analysis of the obtained dependencies explicitly showed that the drives mainly powered by gear-type and vane-type pumps had the maximum time spread of achieving limit values based on the volumetric performance parameter. In order to achieve maximum efficiency of hydraulic drives in operation, this circumstance should be considered in designing new machines on the one hand, and planning the orders for the spare parts on the other hand. It was concluded that the main diagnostic parameters of hydraulic drive and its elements were the volumetric losses of the performance operating liquid.

In addition, the dependencies of changes in volumetric performances of roll drive, linear motion drive, hydraulic actuators, axial piston hydraulic machines, spool valves, and gear and vane pumps were constructed. In this study, the complexes of organization and technical measures for maintenance and repair carried out as planned were integrated into the single planned preventive system.

\section{References}

1. Kharazov, A.M. "Research and development of the ways and means for diagnostics of hydraulic drives of construction machines by the example of E-153 and E-1514 excavators", Thesis of Candidate of Technical Science, MADI, Moscow, Russian Federation, pp. 3943 (1972).

2. Kharazov, A.M. "Technical diagnostics of hydraulic drives of machines", Machine Engineering, 5, Moscow, pp. 79-82 (1979).

3. Birger, I.A., Technical Diagnostics, Machine Engineering, Moscow, pp. 34-36 (1978).

4. Verzakov, G.F. "Introduction into technical diagnostics", Energy, Moscow, 36, pp. 20-23 (1968).

5. Petrov, I.V. "Diagnostics of road construction machine", Transport, Moscow, 17(3), pp. 103-105 (1980).

6. Kim, B.G. "Increase in preparedness of construction fleets by improving the maintenance", Thesis of Doctor of Technical Sciences, VlSU, Vladimir, Russian Federation, p. 47 (1996).

7. Terskikh, I.P. "Scientific aspects of functional diagnostics (performance) of machine-tractor aggregates", Thesis of Doctor of Technical Sciences, IRNRTU, Irkutsk, Russian Federation, pp. 54-58 (1973).

8. Alekseeva, T.V., Zagrebelniy, V.I., and Kolosov, S.V. "Technical diagnostics of hydraulic drives", Machine Engineering, Moscow, 11, p. 62 (1989).

9. Abramov, S.I. and Kharazov, A.M. "Technical diagnostics of single-bucket excavators with hydraulic drive", Stroyizdat, Moscow, 17, pp. 98-104 (1978). 
10. Korzhov, V.A. "Technical diagnostics of flying vehicles', hydraulic systems aggregates", Thesis of Candidate of Technical Sciences, Riga, Latvia, pp. 18-34 (1975).

11. Makarov, R.A. and Sokolov, A.V. "Diagnostics of construction machines", Stroyizdat, Moscow, 143, pp. 77-89 (1984).

12. Maltseva, N.A. "Improvement of maintenance of road construction machines by applying the means of technical diagnostics", Thesis of Candidate of Technical Sciences, OmSTU, Omsk, Russian Federation, pp. 1519 (1980).

13. Morozova, S.S. "Development and introduction of method for predicting reliability of construction machines based on the analysis results of engine oils and hydraulic liquids", Thesis Abstract of Candidate of Technical Sciences, Center for Transport Technology Ltd, Moscow, pp. 34-39 (1984).

14. Pavlov, A.I. "Substantiation and development of the methods and means for diagnosis of the timber harvesting machines' hydro system elements", Thesis of Candidate of Technical Sciences, SPbPU, Leningrad, pp. 83-86 (1982).

15. Ponomarenko, Y.F. "Hydraulic drives testing", $M a$ chine Engineering, Moscow, pp. 69-78 (1969).

16. Sidorov, V.N. "Research of the cross functional excavators' hydraulic drives diagnostic processes", Thesis of Candidate of Technical Sciences, SPbPU, Leningrad, Russian Federation, pp. 61-63 (1980).

17. Shumeyko, S.V. "Research and development of the methods and devices for diagnostics of the powered roof supports' hydraulic drives technical state", Thesis of Candidate of Technical Sciences, MADI, Moscow, Russian Federation, pp. 46-54 (1985).

18. Bagin, S.B., Development and Creation of SingleBucket Excavator's Hydraulic Drive Diagnostics System, SPbPU, Leningrad, pp. 18-31 (1987).

19. Nikitin, O.F., Reliability, Diagnostics and Operation of Mobile Objects' Hydraulic Drive: Lecture Course with Problems Solution, Bauman MSTU Publishing Office, Moscow, pp. 27-34 (2007).

20. Baryshev, V.I., Reliability and Diagnostics of Hydraulic Drive: Study Guid, SUSU Publishing Office, Chelyabinsk, pp. 125-137 (2003).

21. Grinchar, N.G. "Reliability of hydraulic drives of construction, track and carrying and lifting machines", In Study Guide for Universities, SMC RRT, Moscow, pp. 248-254 (2007).

22. Karakulev, A.V., Ilyin, M.E., and Markedanets, O.V. "Exploitation of construction, track and carrying and lifting machines", Transport, Moscow, 27(10), pp. 1827 (1991).
23. Alexandrova, T.A., Gorlenkov, D.V., and Romanova, N.A. "Researching of influence of tungsten, silicon and impurities oxidation on electrolytic dissolution of $\mathrm{Cu}-$ Zn and Fe-Ni-CO anodes", Periódico Tchê Quimica, 14(28), pp. 9-17 (2017).

\section{Biographies}

Nikolay G. Grinchar graduated from the Moscow Institute of Railway Transport Engineers with a degree in Construction and Track Machines in 1980 with honors and received the $\mathrm{ScD}$ in 2007 . He is a full member of the Russian Academy of Transport with 113 publications. Currently, he is a Professor in the Department of Track Machines, Construction Machines, and Robot Systems at the Russian University of Transport (MIIT).

Pavel A. Sorokin graduated from the Tula Polytechnical Institute with a degree in Aircraft Electrical Equipment in 1972 and received the $\mathrm{ScD}$ in 1996. He became a Professor in 2003. Dr. Sorokin is the winner of S. I. Mosin Awards of 1979 and 2006 and a full member of the Russian Academy of Transport, Russian Academy of Quality Problems, and Ukrainian Academy of Lifting and Transport Sciences. His research interests include structural monitoring of structures for lifting equipment by optoelectronic methods and ensuring stability of crane steel structures under random perturbations. He has more than 200 publications and inventions and is currently working as a Professor in the Department of Track Machines, Construction Machines, and Robot Systems at the Russian University of Transport (MIIT).

Vladimir A. Karpychev graduated from the Moscow Institute of Railway Engineers with a degree in Locomotives and Locomotive Facilities in 1983 and received the $\mathrm{ScD}$ in 2001. He is a full member of the Russian Academy of Quality Problems. Dr. Karpychev holds an honorary position in Education of the Russian Federation with 52 publications. Currently, he is working as the Head of the Department of Machine Science, Design, Standardization, and Certification at the Russian University of Transport (MIIT).

Konstantin A. Sergeev graduated from the Moscow Institute of Railway Engineers with a degree in Rail Cars and Rail Car Facilities in 1967 and received the $\mathrm{ScD}$ in 2006. He has 177 publications and is currently working as the Head of the Department of Non-traction Rolling Stock at the Russian University of Transport (MIIT). 